\title{
PLASTIC RESPONSE OF THIN-WALLED TUBES TO DETONATION
}

\author{
J. Karnesky, J. Damazo; J. E. Shepherd \\ Explosion Dynamics Laboratory \\ California Institute of Technology \\ Pasadena, California, USA \\ Email: damazo@caltech.edu
}

\author{
A. Rusinek \\ Laboratory of Mechanic, Biomechanic, Polymers and Structures \\ National Engineering School of Metz (ENIM) \\ lle du Saulcy, Metz cedex, 57045 \\ France
}

\begin{abstract}
Elastic and plastic deformation of tubes to internal detonations and the shock waves produced by their reflection were investigated. The study included experimental measurements as well as computational modeling. Tests with stoichiometric ethylene-oxygen mixtures were performed at various initial pressures and strain was measured on thin-walled mild-steel tubes. The range of initial pressures covered the span from entirely elastic to fully plastic deformation modes. A model for the pressure load on the tube wall was developed and tested against experimental measurements. This model was applied as a boundary condition in both a single degree of freedom model of the tube cross section and a finite element model of the entire tube. Comparison of computational and experimental results showed reasonable agreement if both strain-rate and strain-hardening effects were accounted for. A unique mode of periodic radial deformation was discovered and explained through modeling as the result of flexural wave interference effects.
\end{abstract}

\section{NOMENCLATURE}

$c$ Speed of sound in gas

$f$ Temporal frequency of oscillation

$h$ Thickness of tube wall

$u$ Fluid velocity

$x$ Change in tube radius

CJ Theoretical Chapman-Jouget, post-detonation state

$E$ Young's modulus

\footnotetext{
*Address all correspondence to this author.
}

$P \quad$ Internal pressure of tube

$R$ Undeformed tube radius

$U_{C r}, U_{R}$ Detonation and reffecting shock velocities

$X$ Axial location of reflected shock

$\gamma$ Ratio of specific heats

$v$ Poisson ratio

$\rho$ Density of tube material

$\tau$ Time decay constant in pressure model

$\omega$ Angular frequency of oscillation

\section{INTRODUCTION}

Detonation waves $[1,2]$ are shock waves coupled with and supported by a reaction zone. When a combustible mixture in a pipe undergoes detonation, the detonation wave propagates from the point of ignition to the end of the pipe [3]. When the detonation reaches the closed end of a pipe, a reflected shock wave is formed to bring the flow immediately behind the detonation to zero velocity [4]. This shock wave has an initial pressure of approximately $2.4-2.5$ times [4] the pressure of the incident detonation wave. The shock decays as it propagates into the unsteady flow field of the detonation products. These pressure waves excite vibrations of the tubes and the elastic response has been extensively studied [5]. Depending on the tube geometry and the pressure of the incident detonation, the transient pressure immediately following the detonation reflection may be sufficiently high to result in plastic deformation or rupture of the tube.

In order to investigate the plastic deformation case, a series of experiments was conducted in which detonations were propagated within thin-walled steel tubes and reflected from a nearly

Copyright (c) 2010 by ASME 
rigid, reflecting boundary at the closed end. The large pressures associated with the detonation and reflection resulted in plastic deformation of the tubes. In order to measure deformation, the tubes were instrumented with 20 strain gauges, concentrated in the vicinity of the reflecting end where the large-scale plastic deformation occurred. A high-speed camera was used to monitor the deflection of the tube wall at the reflecting end. Stoichiometric ethylene-oxygen was used as the test mixture at initial pressures of $0.5,1,2$, and 3 bar. Plastic deformation was observed to occur in all but the 0.5 bar cases. Repeated 2 and 3 bar experiments were performed in the same tube specimens to investigate the plastic strain ratcheting.

Pressure measurements and a simple model of reflection were used to develop an idealized internal loading history. The structural response of the tube was modeled using this ideal load history and a single degree of freedom model was employed as well as a 2-D, axisymmetric finite element model.

\section{EXPERIMENT DESCRIPTION}

The primary motivation of this series of experiments was to obtain detailed plastic strain measurements on a tube subjected to a well-defined detonation/reflected shock loading with known boundary conditions. The experimental setup is illustrated in Fig. 1. The entire assembly is mounted on a track and an inertial mass is bolted to the far-right fixture. The test specimens were flush-controlled welded, cold-rolled tubes comprised of ASTM specification A513, type 2, material type C1010 mild steel, with an inner diameter of $127 \mathrm{~mm}$, a wall thickness of $1.5 \mathrm{~mm}$, and a length of $1.2 \mathrm{~m}$. The elastic modulus was assumed to be $E=210 \mathrm{GPa}$, the Poisson ratio was assumed to be $v=0.3$, and the density was assumed $\rho=7850 \mathrm{~kg} / \mathrm{m}^{3}$. These tubes were coupled with a thick-walled tube of the same internal diameter and length. Within the thick-walled driver tube, the detonation was initiated and allowed to accelerate to a nearly ideal CJ (Chapman-Jouguet) speed before entering the test specimen. This thick-walled tube contained a glow plug to initiate a flame and obstacles to promote flame acceleration and DDT (deflagration to detonation transition), it was instrumented with pressure transducers along the wall in order to ensure that a fully developed detonation propagated into the specimen tube.

The driver and specimen tubes were sealed in the center by a flange with two internal gland seals. This flange mated with a face-seal onto the open end of the thick driver tube, and the thin specimen tubes slipped into the gland seals. In order to achieve the desired fixed boundary condition, a collet was designed to clamp down on the reflecting end of the specimen tube. The collet was cut by wire-EDM out of tool steel and hardened. At $10 \mathrm{~cm}$ in length, the collet was designed such that the end point of the collet, when tightened, matched the face of the reflecting surface of the aluminum plug located inside the tube. A ring with an internal taper forced the collet closed and was bolted to a plate using $89 / 16 "-18$ bolts with minimum preloads of $68 \mathrm{~N}-$ $\mathrm{m}$, resulting in a clamping force of at least $65,000 \mathrm{~N}$. The collet assembly was securely fastened to a $2700-\mathrm{kg}$ steel mass to ab- sorb the recoil of the reflecting detonation. The collet and driver tube were held together with chains to prevent the force of the detonation from pulling the test specimen and driver tubes apart.

The specimen tube was instrumented with 20 strain gauges. The model number and placement of these strain gauges varied between specimen tubes, but in general the strain gauges were concentrated near the reflecting end where the maximum deformation was observed to occur. In addition to 3 pressure gauges in the driver tube, there was also a pressure gauge located in the center of the aluminum plug at the reflecting end. The location of strain and pressure gauges for specimen tubes 4 and 7 are summarized in Tables 1 and 2. Post shot diameter and thickness measurements were taken using an outside micrometer and a Checkline TI-007 ultrasonic wall-thickness gauge.

In each experiment, the tube assembly was filled with stoichiometric ethylene-oxygen to initial pressure of $0.5,1,2$, or 3 bar. Plastic deformation was observed for each case except those with initial pressures of 0.5 bar. Repeated experiments on the same specimen tubes were performed with initial pressures of 2 and 3 bar to investigate strain ratcheting. Seven specimen tubes were used in this series. All of the testing was reported in [6]. Here we will restrict discussion to tubes 4 and 7 which yielded the best results.

\section{RESULTS FROM SPECIMEN TUBE 4}

The goal of the experiments performed in this tube was to investigate the strain ratcheting resulting from detonations of initial pressure 2 bar. Tube 4 was tested with 11 detonations, 5 shots resulted in plastic deformation with initial pressure 2 bar and 6 were elastic shots performed at initial pressure 0.5 bar to ensure that the gauges and data acquisition system were functioning properly.

\section{TABLE 1. GAUGE LOCATIONS FOR TUBE 4, DISTANCES FROM REFLECTING END}

\begin{tabular}{|r|c|c|c|c|c|}
\hline Pressure & $\mathrm{P} 1$ & $\mathrm{P} 2$ & $\mathrm{P} 3$ & $\mathrm{P} 4$ & \\
$\mathrm{~mm}$ & 1568 & 1441 & 1314 & 0 & \\
\hline Hoop Strain & $\mathrm{S} 1$ & $\mathrm{~S} 2$ & $\mathrm{~S} 3$ & spacing & $\mathrm{S} 20$ \\
$\mathrm{~mm}$ & 845 & 540 & 235 & 19 & 6.4 \\
\hline Long. Strain & $\mathrm{S} 7$ & $\mathrm{~S} 10$ & $\mathrm{~S} 13$ & $\mathrm{~S} 16$ & $\mathrm{~S} 19$ \\
$\mathrm{~mm}$ & 178 & 140 & 102 & 64 & 25 \\
\hline
\end{tabular}

Tube 4 utilized two types of strain gauges: 5 strain gauge rosettes placed near the reflecting end and 10 single-element gauges, the majority of which were also placed near the reflecting end. Each of the five rosettes (Vishay C2A-06-125LT-350) had two strain gauge elements oriented at $90^{\circ}$ angles to one another. The gauges were oriented such that the directions of measurement were the hoop and longitudinal direction, and placed 


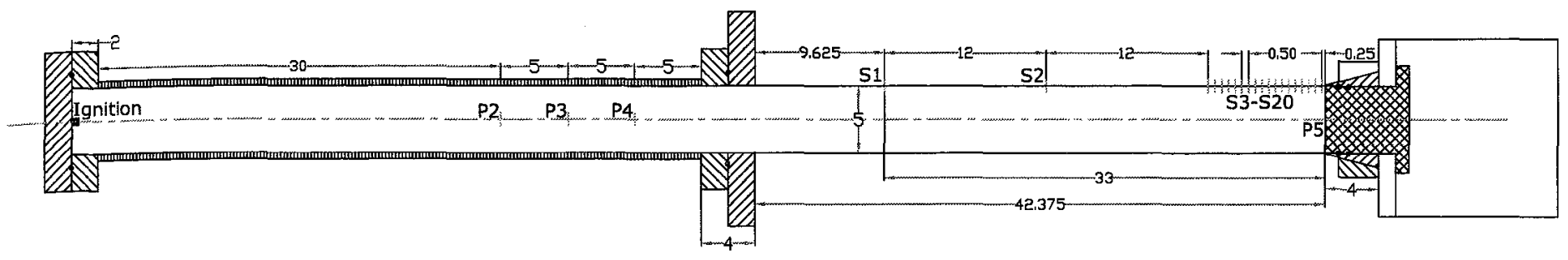

FIGURE 1. DETONATION TUBE

such that the hoop and longitudinal elements had the same axial location. The rosette farthest downstream was located $6.4 \mathrm{~mm}$ from the reflecting end. In addition to the rosettes, there were 10 single-element strain gauges (Vishay C2A-06-125LW-350) oriented to measure strain in the hoop direction and spaced between the rosettes such that the rosettes and single-element gauges alternated with a spacing of $19.1 \mathrm{~mm}$ between gauges. In addition to those gauges clustered at the reflecting end, 2 hoop gauges were located at more central locations in the tube to observe the strain behavior far from the boundary conditions. The layout of the measurement locations is summarized in Table 1; note strain gauges S7, S10, S13, S16, and S19 are oriented in the longitudinal direction and the remaining strain gauges are hoop gauges. The spacing entry in Table 1 is the separation between hoop strain gauges S3 through S20. I.e., S3 is at the listed distance of $235 \mathrm{~mm}$ from the reflecting end and each subsequent hoop gauge is $19 \mathrm{~mm}$ closer up to the last gauge $\mathrm{S} 20$ at $6.4 \mathrm{~mm}$ from the end. In addition to the strain gauges, a high speed camera was used to monitor the plastic deformation of the tube wall.

The deformed tube is shown in Fig. 2 against a $5 \mathrm{~mm}$ grid. Figures 3 and 4 contain representątive hoop and longitudinal

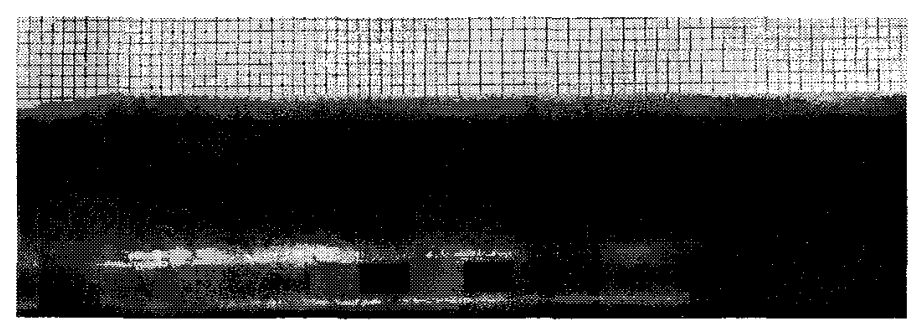

FIGURE 2. TUBE 4 AFTER 5 DETONATIONS OF INITIAL PRESSURE $P_{0}=2$ bar. THE GRID SPACING IS $5 \mathrm{~mm}$.

strain traces from the five tests at 2 bar initial pressure. Examining Fig. 3 and 4 we see three definitive times that show changes in the strain behavior. The first change in strain is a rise in longitudinal strain and a corresponding, but barely visible, dip in hoop strain (indicating a decrease in tube diameter). These strains are the result of the longitudinal wave that is excited by the detonation and travels at the bar speed of the tube. Approximately $0.1 \mathrm{~ms}$ after the small dip is observed, the hoop strain undergoes a sudden increase and begins to oscillate at the cross-sectional

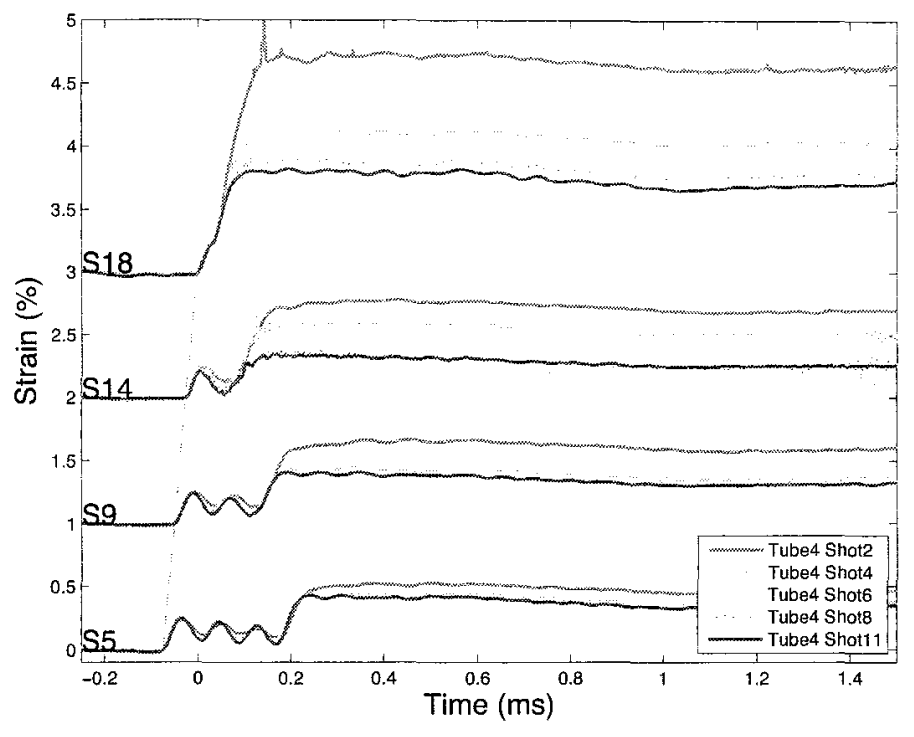

FIGURE 3. HOOP STRAIN IN TUBE 4 DURING 5 SUBSEQUENT DETONATIONS OF $P_{0}=2$ bar

natural frequency. This strain increase results from the flexural waves that travel with the detonation [5]. As shown in Fig. 3, the detonation travels from S5 towards S18. When the detonation reaches the end-wall, a reflected shock wave is created and propagates back into the tube from $\mathrm{S} 18$ to $\mathrm{S} 5$. The peak pressure (and hence the strain) is highest for times soon after the detonation reflects.

The repeated tests show a substantial effect of strain hardening. The plastic strain increment on the first shot of a test series is always higher than that of the second and subsequent shots. This is particularly pronounced near the reflecting surface (gauge $\mathrm{S} 18$ ). One interesting feature of the deformation resulting from repeated shots was the formation of periodic ripples in the tube, shown in Fig. 5. The ripples had a mean peak-to-peak spacing of $63.0 \mathrm{~mm}$. The distance between successive peaks was monotonically increasing away from the reflected end, with incremental gains per cycle averaging $1.3 \mathrm{~mm}$. Figure 6 gives the measurements of the outer diameter in the vicinity of the reflecting end taken after each plastic shot. The computational work described below explains this behavior.

Since each longitudinal gauge was accompanied by a hoop gauge, we were able to examine the ratio between longitudinal 


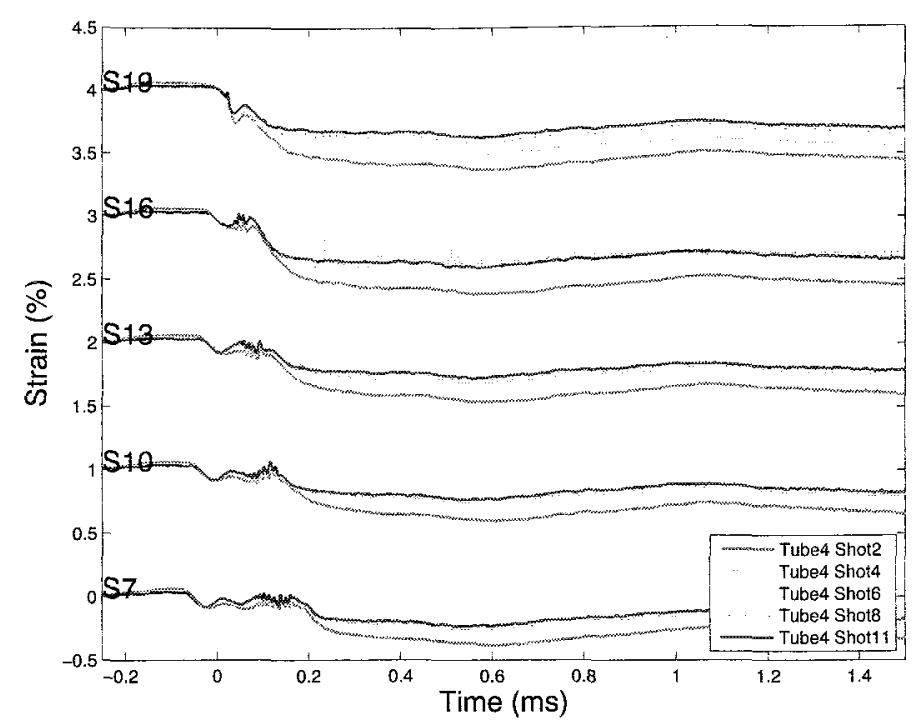

FIGURE 4. LONGITUDINAL STRAIN IN TUBE 4 DURING 5 SUBSEQUENT DETONATIONS OF $P_{0}=2$ bar

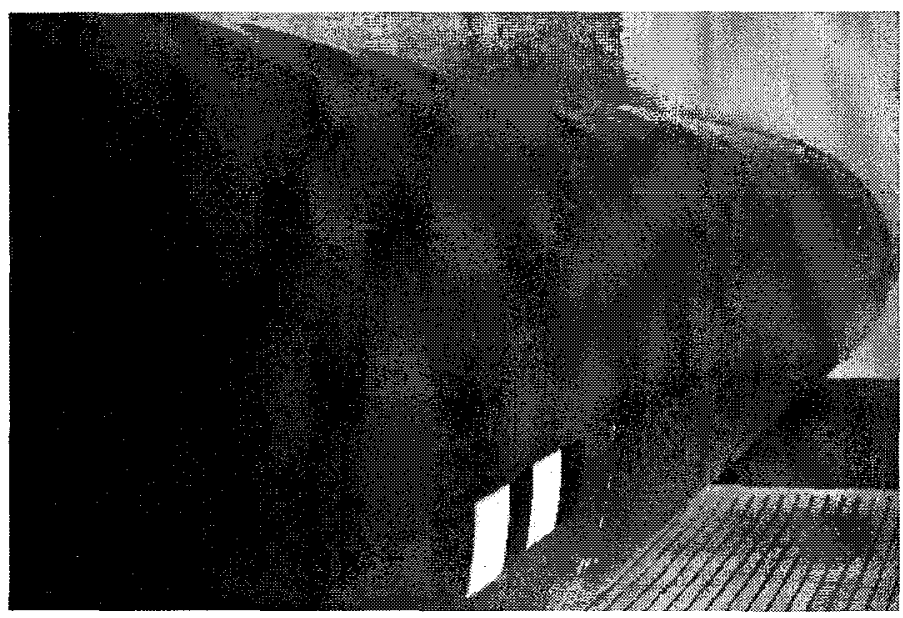

FIGURE 5. RIPPLING IN TUBE 4 AFTER 5 DETONATIONS OF $P_{0}=2$ bar

and hoop strains. Figure 7 shows the ratio $-\varepsilon_{\text {long }} / \varepsilon_{\text {hoop }}$ averaged for times of 1 to $50 \mathrm{~ms}$ for each rosette and each plastic shot. The value for the strain ratio fluctuates from shot to shot and gauge to gauge, but there is a discernible trend. For all rosettes except that closest to the reflecting end, we observe that the strain ratio is noticeably higher for the first experiment then for subsequent experiments. This is due to the fact that we see much more plastic strain for this particular shot. For the strain gauge rosette nearest the reflecting end, the ratio is approximately constant for all experiments. This is likely caused by the non-negligible effects from the boundary where there is a sharp change in tube diameter as seen in Fig. 6 and a noticeable change in wall thickness.

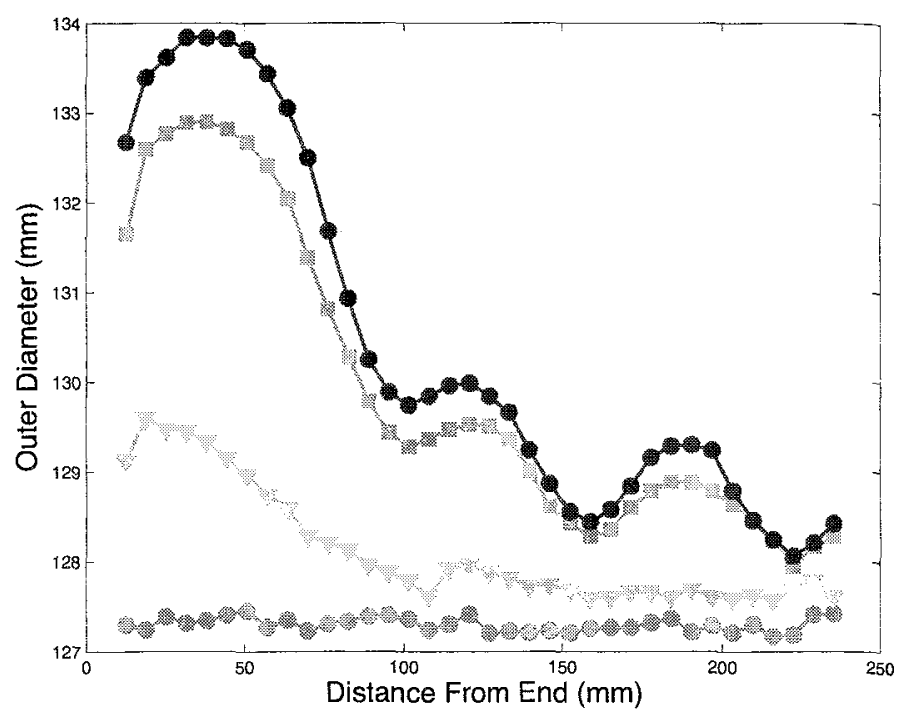

FIGURE 6. OUTER DIAMETER OF TUBE 4 AFTER EACH OF 5 DETONATIONS OF $P_{0}=2$ bar

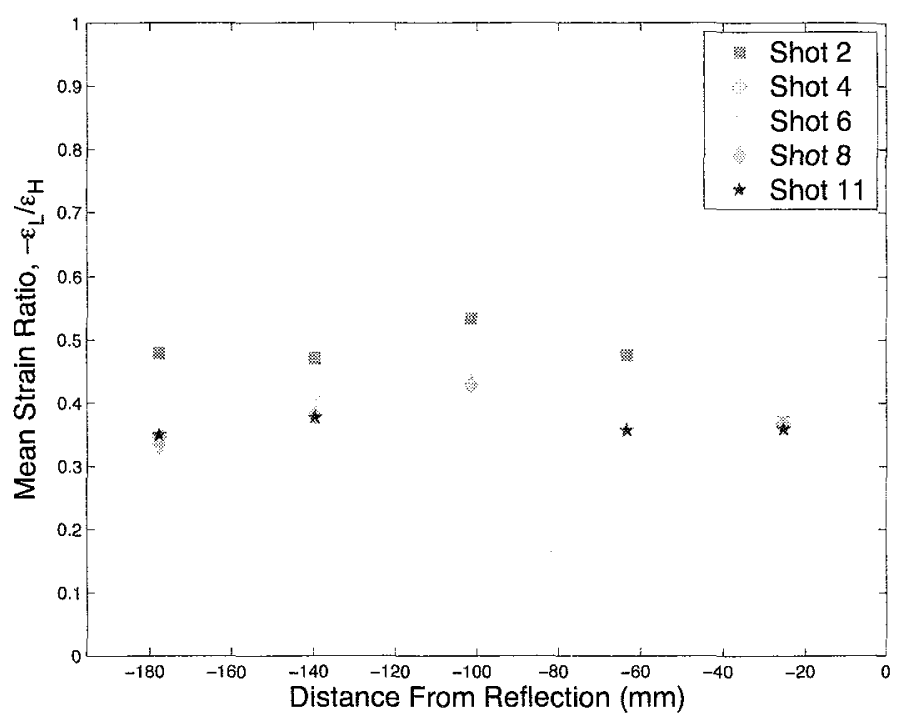

FIGURE 7. STRAIN RATIO FOR EACH PLASTIC EXPERIMENT

\section{RESULTS FROM SPECIMEN TUBE 7}

For the series of repeated tests at 3 bar initial pressure, the change from the Vishay C2A-06-125LW-350 gauges to EP-08125AC-350 gauges were made. Utilizing an epoxy for bonding instead of the typical cyanoacrylate adhesive, these gauges were specified to be able to measure up to $20 \%$ strain; a requirement for the large deformations associated with an initial pressure of 3 bar. The gauge layout for tube 7 omitted longitudinal strain measurement in favor of superior coverage of the axial span of the plastic deformation at the end wall. The new gauge configuration is given in Table 2. Akin to Table 1, the spacing term refers to the separation distance between subsequent strain gauges. A total of 8 experiments were performed in tube 7 ; three 
TABLE 2. GAUGE LOCATIONS FOR TUBE 7, DISTANCE FROM REFLECTING END

\begin{tabular}{|r|c|c|c|c|c|}
\hline Pressure & P1 & P2 & P3 & P4 & \\
$\mathrm{mm}$ & 1568 & 1441 & 1314 & 0 & \\
\hline Hoop Strain & $\mathrm{S} 1$ & $\mathrm{~S} 2$ & $\mathrm{~S} 3$ & spacing & S20 \\
$\mathrm{mm}$ & 845 & 540 & 222 & 13 & 6.4 \\
\hline
\end{tabular}

at 3 bar initial pressure and 5 elastic experiments at $50 \mathrm{kPa}$ to test the apparatus.

Initially, these tests showed the same hardening behavior as the 2 bar series. However, after a large reduction in strain increment due to hardening between the first two shots, the third shot showed a reduced effect of hardening. This is shown in Fig. 8.

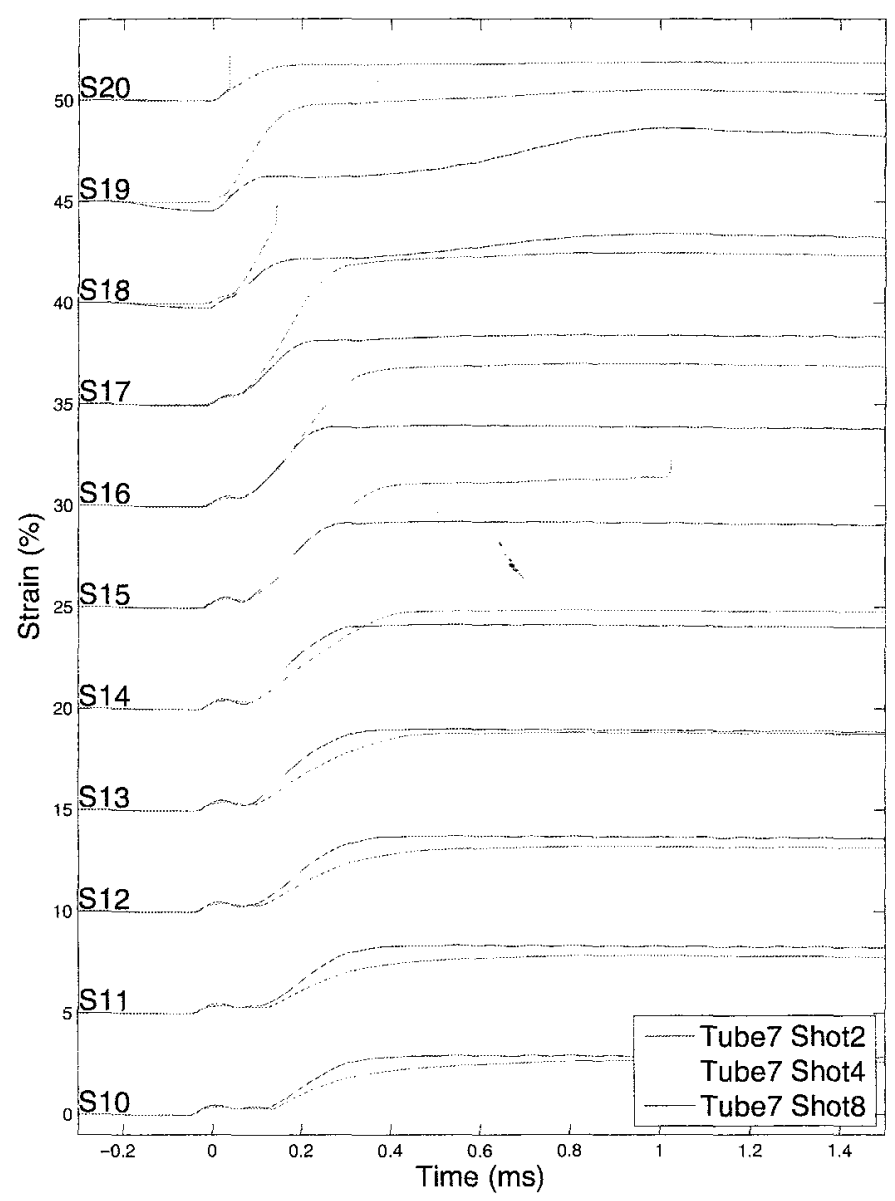

FIGURE 8. HOOP STRAIN IN TUBE 7 DURING 3 SUBSEQUENT DETONATIONS OF $P_{0}=3$ bar. TIMES AT WHICH DATA SPIKES OR CEASES REPRESENT GAUGE FAILURE.

The third plastic shot in the tube also demonstrated a very interesting behavior in the vicinity of the reflecting boundary, as shown in Fig. 9. The first thing to notice is that the precursor is

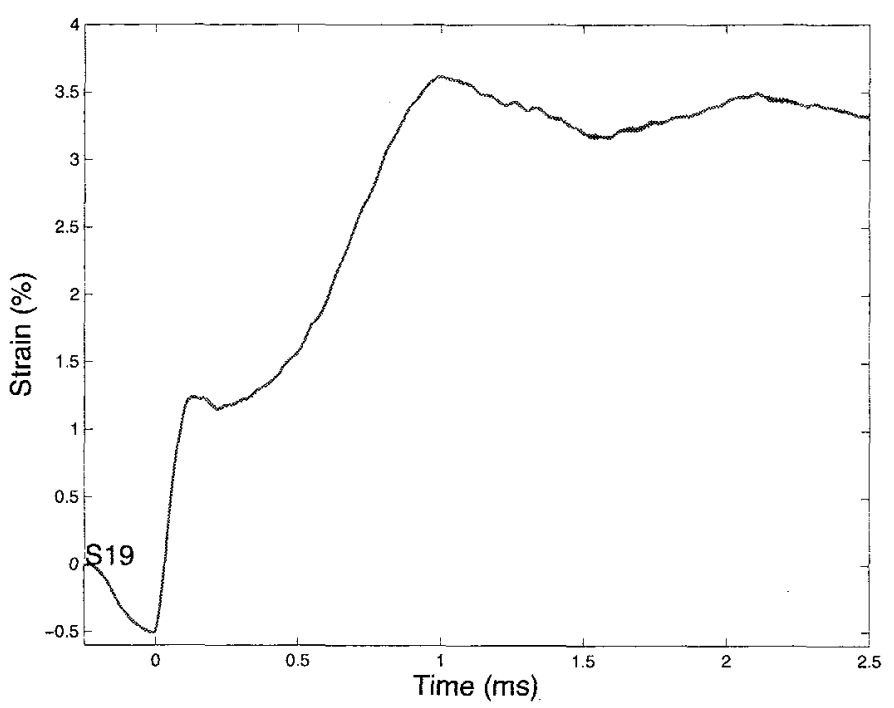

FIGURE 9. HOOP STRAIN MEASURED $19 \mathrm{~mm}$ FROM THE REFLECTING END IN TUBE 7, SHOT 8 WITH INITIAL PRESSURE $P_{0}=3$ bar

an order of magnitude larger than in the previous tests, peaking at $0.5 \%$ strain-well into the plastic regime. After this, the initial deformation of the tube due to the detonation and reflected shock wave follow the familiar pattern, occuring over $0.1 \mathrm{~ms}$. Then, over the first millisecond following reflection, the strain continues to rise at a slower rate to a peak strain of three times that caused by the impulse of the reflected shock. A long-period vibration then sets in that is localized to the tube's reflecting end.

The cause of these behaviors remains unclear. However, one thing that is known is that the tube has undergone a large amount of plastic deformation and strain gauge 19 is at the elbow shown in Fig. 10 where the slope of the tube wall is drastic. Although

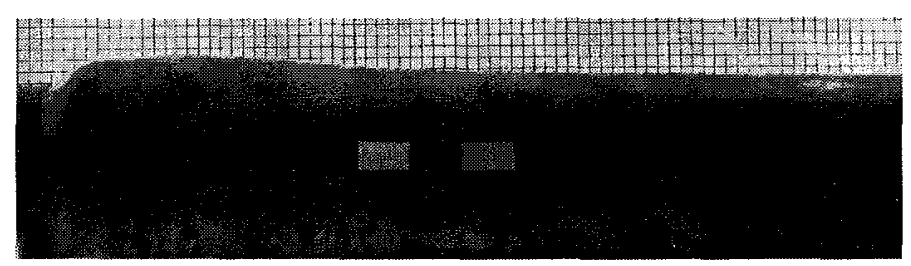

FIGURE 10. TUBE 7 AFTER 3 DETONATIONS OF INITIAL PRESSURE $P_{0}=3$ bar. THE GRID SPACING IS $5 \mathrm{~mm}$.

the exact mechanism is unknown, it seems reasonable that this region of large variation in tube diameter and wall thickness would influence the longitudinal waves and perhaps cause the unexpectedly high strains before the detonation arrives. 
It is also noteworthy that the frequency of the long-period vibration is on the same order as the breathing mode of the entire tube shown in Fig. 11 as predicted by commercial finite element software [7] using a cylindrical shell with fixed boundaries. A

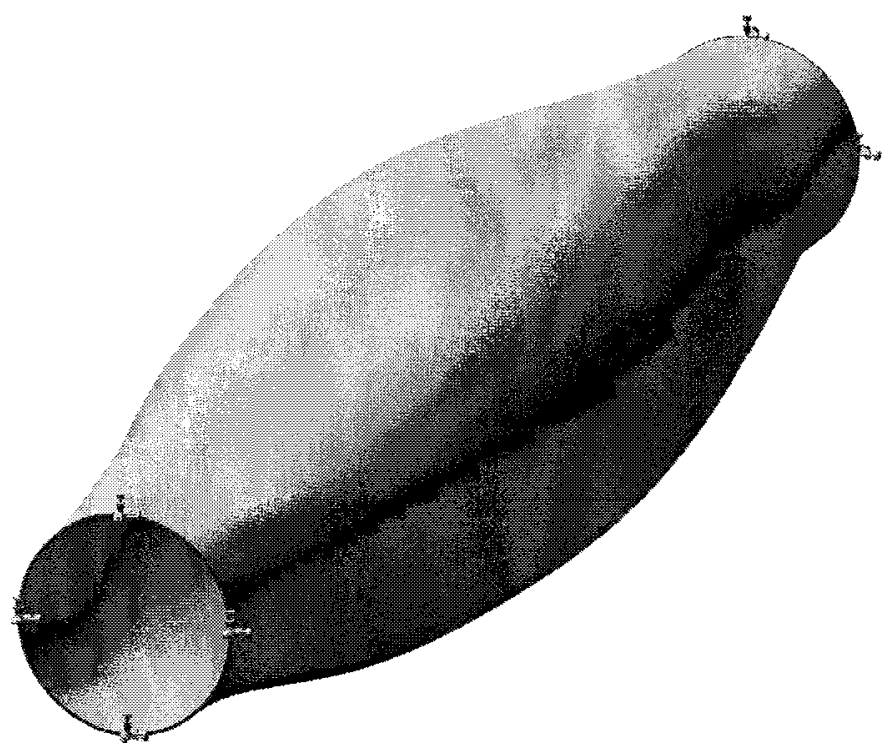

FIGURE 11. PREDICTION OF THE BREATHING MODE OF THE ENTIRE TUBE, $f=1520 \mathrm{~Hz}$ [7]

discrete Fourier transform from the data for the 3 bar plastic deformation experiments was not useful as the slower frequencies $(f<10 \mathrm{kHz})$ were blurred over a range of 0 to approximately $4000 \mathrm{~Hz}$ due to the complexity of the signals. However, this mode is clearly seen in a discrete Fourier transform of the elastic strain data where the experiment reveals peaks at 13120 and 1556 $\mathrm{Hz}$. The higher frequency oscillation is that of the single degree of freedom hoop oscillation mode (the rapid oscillation visible in Figs. 3 and 8) and the slower oscillation corresponds closely to the breathing mode of the entire tube shown in Fig 11 with an oscillation frequency of $1520 \mathrm{~Hz}$. Studying the thickness measurements of the tube shown in Fig. 12 reveals that although the thickness measurement after the first 3 bar test showed largely the same qualitative behavior as the measurements made in tube 4 , the measurements taken after the second 3 bar test are very different. There is a $38 \mathrm{~mm}$ wide region of near-constant thickness which shows a sharp decrease in thickness from the surrounding material, unseen in previous tests. This indicates that necking occurred in the material during the test. Therefore we speculate that in the 2 bar tests and earlier 3 bar tests the force associated with the mode shown in Fig. 9 was absorbed by the boundary, but the combination of the necking and the rapid change in the tube outer diameter meant that, in the later 3 bar tests, this force was instead supported by the tube wall and resulted in the observed long-time oscillating strain behavior. I.e., it appears that this region is acting as a plastic hinge responding to the breath- ing mode displayed in Fig. 11. This also explains why the peak

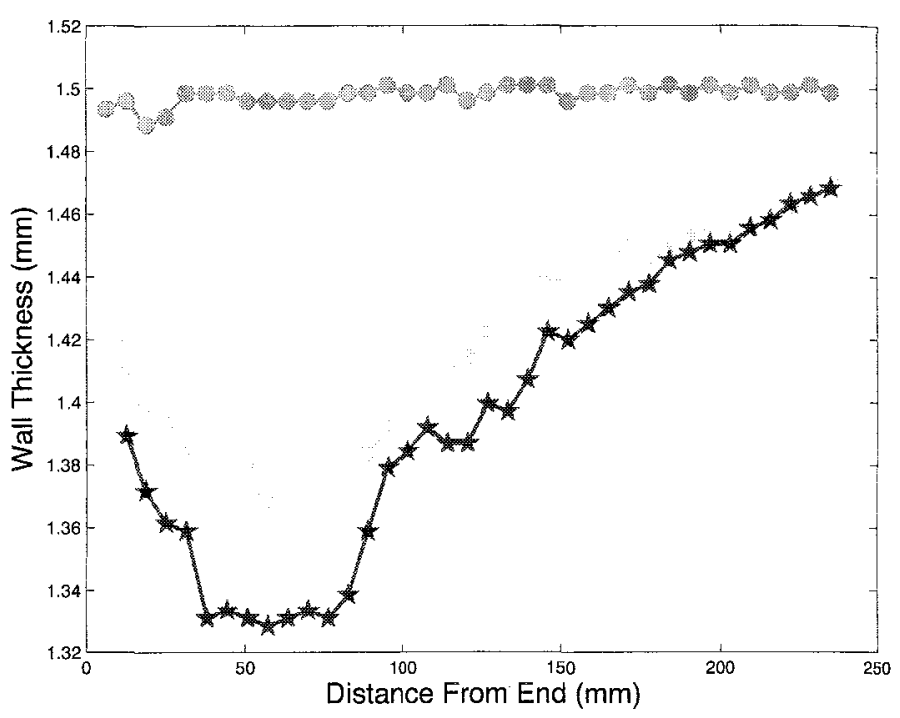

FIGURE 12. WALL THICKNESS OF TUBE 7 AFTER EACH OF 3 DETONATIONS OF $P_{0}=3 \mathrm{bar}$

outer diameter increased between the two tests; strain hardening would tend to decrease this change (as was observed for the 2 bar tests), but the plastic instability causes large strains.

Because the point of plastic instability was approached in these tests, and the experimental facility was not set up to contain blast waves resulting from tube rupture, no further plastic experiments were performed in tube 7 .

\section{COMPUTATIONS}

The experiment was simulated with a single degree-offreedom model and also a finite element computation was performed. A description of the pressure load on the tube wall was required for these computations and thus a semi-empirical model for the pressure was developed, validated, and applied to the finite element mesh.

\section{PRESSURE LOADING MODEL}

The reflection of a detonation wave from the closed end of a tube produces an unsteady flow field and a decaying shock wave. In order to numerically compute the structural response of the tube arising from a detonation and its reflection, it is necessary to specify the pressure history everywhere along the tube interior. Although this can be done with computational fluid dynamics, we have developed a simple alternative in the form of a semi-empirical model based on analysis and experimental observations. 


\section{MODEL DESCRIPTION}

Detonation waves propagating inside of a closed tube create a pressure wave that travels from the point of ignition toward the closed end of the tube. The gas immediately behind the detonation wave is moving but is slowed down to zero velocity by the expansion wave following the detonation. This expansion wave is known as the Taylor or Taylor-Zel'dovich wave for their $[8,9]$ derivations of the flow field. The spatial and temporal distribution of pressure for the entire tube prior to the arrival of the reflected shock wave may be solved for explicitly from the method of characteristics $[2,4,10]$. The resulting pressure distribution is

$$
P(x, t)= \begin{cases}P_{1} & \text { if } U_{C J}<x / t<\infty \\ P_{3}\left[1-\frac{\gamma-1}{\gamma+1}\left(1-\frac{x}{c_{3} t}\right)\right]^{\frac{2 \gamma}{\gamma-1}} & \text { if } c_{3}<x / t<U_{C J} \\ P_{3} & \text { if } 0<x / t<c_{3}\end{cases}
$$

where $\gamma$ is the effective ratio of specific heats in the products computed on the basis of chemical equilibrium (see [11, 12]). The subscript 1 denotes the pre-detonation region, and the subscript 3 denotes the post-expansion region. The Taylor wave parameters may be found from the Chapman-Jouguet state to be

$$
\begin{aligned}
& c_{3}=\frac{\gamma+1}{2} c_{C J}-\frac{\gamma-1}{2} U_{C J}, \\
& P_{3}=P_{C J}\left(\frac{c_{3}}{c_{C J}}\right)^{\frac{2 \gamma}{\gamma-1}}
\end{aligned}
$$

where $c_{C J}$ is the sound speed at $\mathrm{CJ}$ state.

When the detonation wave reaches the end wall, a reflected shock wave is created in order to bring the moving gas immediately behind the detonation wave back to rest. In experiments, this is observed on the pressure transducers as a second pressure pulse following the incident detonation. In order to fully model the pressure, it is necessary to carry out a computational fluid dynamics simulation of the gas dynamics in the tube. However, if we are only interested in the first reflected wave, then it is possible to make some simplifying assumptions and create a semi-empirical model for the amplitude of the reflected wave. At the instant of reflection, the shock wave has a peak pressure of about $2.4-2.5 P_{C J}$ and travels at a much lower speed than the incident detonation. The reflected shock decays in both speed and peak pressure as it moves away from the end wall. Numerical simulations of the flow $[4,13]$ predict that there is a very small pressure gradient between the reflected wave and the end wall until the tail of the expansion wave is reached. One such simulation is shown in Fig. 13. These calculations were done with the reacting Euler equations and one-step chemistry and a second order accurate min-mod slope-limited MUSCL scheme [14]. The conditions were a detonation with nodimensional heat release of $50, \gamma$ of 1.2,overdrive 1.01, and a reduced activation energy of 3.71. The initial condition included the TZ expansion, and the domain is 10,000 half reaction zone widths with a base grid of

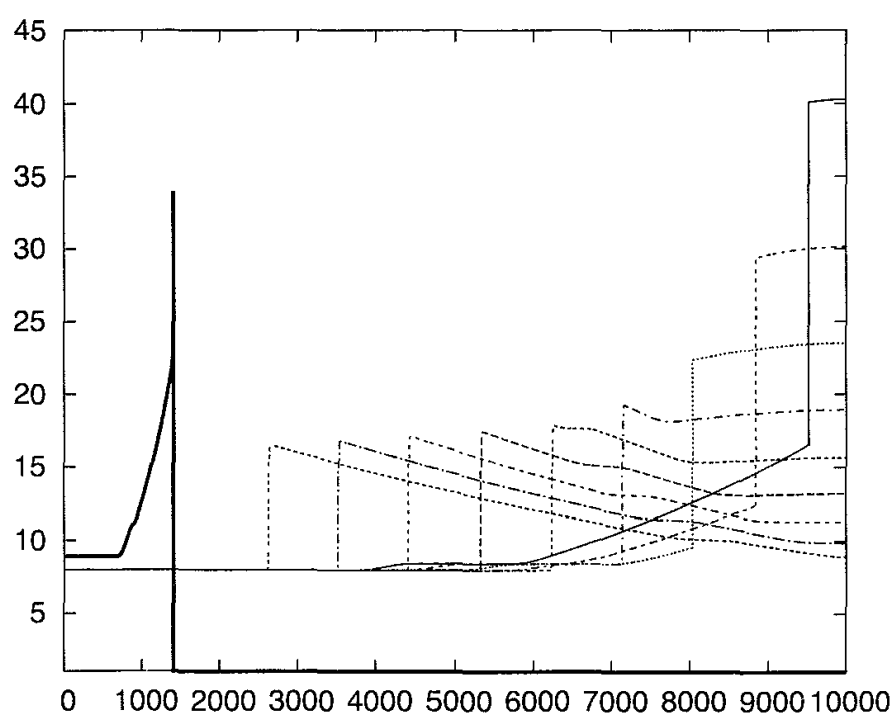

FIGURE 13. SPATIAL PRESSURE PROFILES FROM REACTING EULER CALCULATIONS OF A REFLECTING DETONATION. $x$ AXIS IS HALF-REACTION ZONE WIDTHS, $y$-AXIS IS NORMALIZED PRESSURE [13].

4000 cells and 3 levels of refinement with factors of 2,4 , and 4 [13]. There is a minimal gradient immediately after reflection, when the pressure is highest. As the reflected shock propagates back up the tube and out of the TZ expansion, there is an inflection in this gradient, and it develops into a triangular pulse shape at later times. By this time, however, the post-shock pressure has decayed to below the $\mathrm{CJ}$ pressure of the incident detonation. Based on this observation, we have made the approximation that there is zero pressure gradient behind the reflected shock, so that the pressure just behind the shock is equal to the pressure at the end wall at each point in time. This approximation is only valid for sufficiently short times following reflection. In the case of long times, an expansion wave will develop behind the reflected shock and the pressure gradient cannot be neglected.

Assuming that the pressure $P_{R}$ behind the reflected shock is known, we can use the shock jump relations to find the velocity $U_{R}$ of the reflected shock. The result is

$$
U_{R}(t)=c(x, t) \sqrt{\frac{\gamma+1}{2 \gamma}\left[\frac{P_{R}(t)}{P(x, t)}-1\right]+1}-u(x, t)
$$

where $u(x, t)$ and $P(x, t)$ are the velocity and pressure just upstream (to left) of the reflected shock, as determined by the Taylor wave solution given previously. The trajectory $X_{R}(t)$ of the reflected shock can be determined by integration as

$$
\frac{d X_{R}}{d t}=-U_{R}(t) \quad \text { where } \quad X_{R}\left(t=t_{0}\right)=L
$$

where $t_{0}=L / U_{C J}$ is the time of wave reflection. 
To use our method of computation, the pressure-time history of the shock must be known from either experimental measurement or simulation. Using the zero-pressure gradient assumption discussed above, the present results approximate the reflected shock pressure as the measured pressure history at the end wall $x=L$. The measured pressure history at the end wall for a typical test is shown as P13 in Fig. 14. Since this is quite noisy and the tabulated data is inconvenient for numerical simulation, we have fit the pressure history to a simple exponential decay form as used in previous studies [5] on elastic vibrations of tubes:

$$
P_{R}(t)=P_{C J r e f} \exp \left(-\left(t-t_{o}\right) / \tau\right)+P_{3}
$$

In order to limit the number of parameters that must be obtained from experimental data, we have set the peak pressure $P_{C J r e f}$ and the final pressure $P_{3}$ to be those computed for the ideal reflection of a CJ detonation wave using realistic thermochemistry [15]. The decay time $\tau$ is found by fitting the measured pressure trace to equation (5). The parameters used for our experiment are shown in Table 3. Combining this solution for the reflected

TABLE 3. PARAMETERS USED IN THE PRESSURE MODEL FOR STOICHIOMETRIC ETHYLENE-OXYGEN MIXTURES

\begin{tabular}{|c|c|c|c|c|c|c|}
\hline $\begin{array}{c}\mathbf{P}_{1} \\
\mathbf{b a r}\end{array}$ & $\begin{array}{c}\mathbf{U}_{C J} \\
\mathbf{m} / \mathbf{s}\end{array}$ & $\begin{array}{c}\mathbf{P}_{C J} \\
\mathbf{M P a}\end{array}$ & $\begin{array}{c}\mathbf{c}_{C J} \\
\mathbf{m} / \mathbf{s}\end{array}$ & $\gamma$ & $\begin{array}{c}\mathbf{P}_{r e f} \\
\mathbf{M P a}\end{array}$ & $\begin{array}{c}\tau \\
\mu \mathbf{s}\end{array}$ \\
\hline 0.5 & 2343 & 1.643 & 1264 & 1.138 & 4.120 & 330 \\
\hline 2.0 & 2410 & 6.831 & 1303 & 1.143 & 17.15 & 300 \\
\hline 3.0 & 2430 & 10.54 & 1316 & 1.146 & 26.46 & 2.96 \\
\hline
\end{tabular}

wave with the previous analytical solution for the Taylor wave, the pressure $P(x, t)$ within the tube following detonation reflection is now completely specified.

\section{MODEL VALIDATION}

The experimental setup described above was modified to include pressure gauges in the immediate vicinity of the reflecting end wall so that the pressure of the reflected shock wave may be measured. This entailed cutting holes for the pressure gauges in the wall of the tube and fastening a mount to hold the pressure gauges in place. Since the aluminum mount would only seal to an undeformed tube and the holes cut in the tube wall produced stress concentrations, we could not plastically deform the tube nor would any measured strains be reliably close to the previous experiments. Hence no strain gauges were used in this series of experiments. Four pressure gauges were used in the thick driver tube and 9 pressure gauges were placed on or near the reflecting wall. Pressure gauge P13 was placed in the reflecting wall. Gauge P12 was placed in the reflecting wall $31.8 \mathrm{~mm}$ from the point of reflection so that the gauge's surface was flush with the inner surface of the tube. From P12, P5-P12 were all spaced $12.7 \mathrm{~mm}$ apart in the axial direction except for a $25.4 \mathrm{~mm}$ space between gauges P8 and P9. Figure 14 has the resulting pressure traces spaced proportional to the actual gauge locations.

There are two measures of fidelity that determine the accuracy of this model. The first is the speed of the reflected shock wave and the second is the pressure profile. Figure 14 shows that

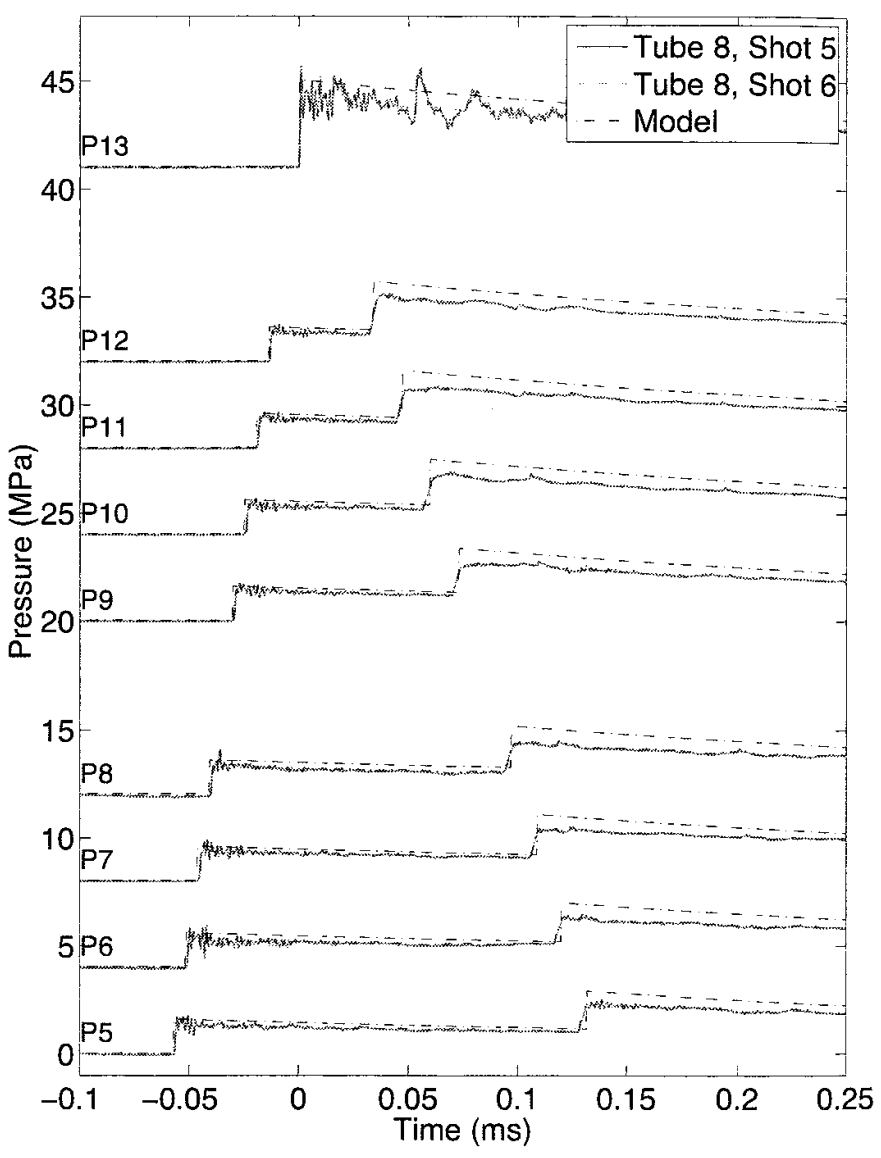

FIGURE 14. PRESSURE-TIME TRACES FOR ALL REFLECTING END GAUGES. DATA FROM TWO SUBSEQUENT DETONATIONS ARE SHOWN TO ILLUSTRATE EXPERIMENT REPEATABILITY.

the model predicts the arrival time accurately, the mean error in arrival time for these gauges was $2.3 \mu \mathrm{s}$. The mean error in arrival time for these gauges was $2.3 \mu \mathrm{s}$. The model is less accurate in predicting the peak pressure-the model tends to over-predict peak pressures on the reflected shock by up to $20 \%$.

The pressure gauges nearest the reflecting end also reveal a behavior that is not captured by our model. When the reflected wave arrives, the model predicts a sharp increase in pressure; however, the data show a more gradual rise. This is especially evident in gauges 11 and 12. This is most likely due to re- 
flected shock wave bifurcation resulting from shock wave boundary layer interaction. Near the tube wall there is a boundary layer that transitions the flow from the velocity behind the detonation wave to zero velocity at the tube wall. As the shock wave reflects into this boundary layer a compression wave, or series of shocks, results rather than a single shock.

Despite the discrepancies in the amplitude of the pressure peaks for the reflected wave, the data seen in Fig. 14 illustrate the usefulness of this model in predicting the speed and strength of the incident detonation and reflected shock wave. We used this model of the pressure loading in the single degree of freedom and finite element calculations described below.

\section{MATERIAL MODEL}

In addition to a model for the pressure load on the tube wall, the constitutive relations for the tube material are needed for structural simulations. Specimens of the tube wall were subjected to testing to measure the constitutive relations. The dynamic response of the material was assessed in a double shear test (described by Rusinek and Klepaczko [16] and reported in [17]) for strain rates of $\dot{\varepsilon}=10^{-3}$ to $10^{2} \mathrm{~s}^{-1}$. The results are shown in Fig. 15. A shear test was used to reach high strain rates with

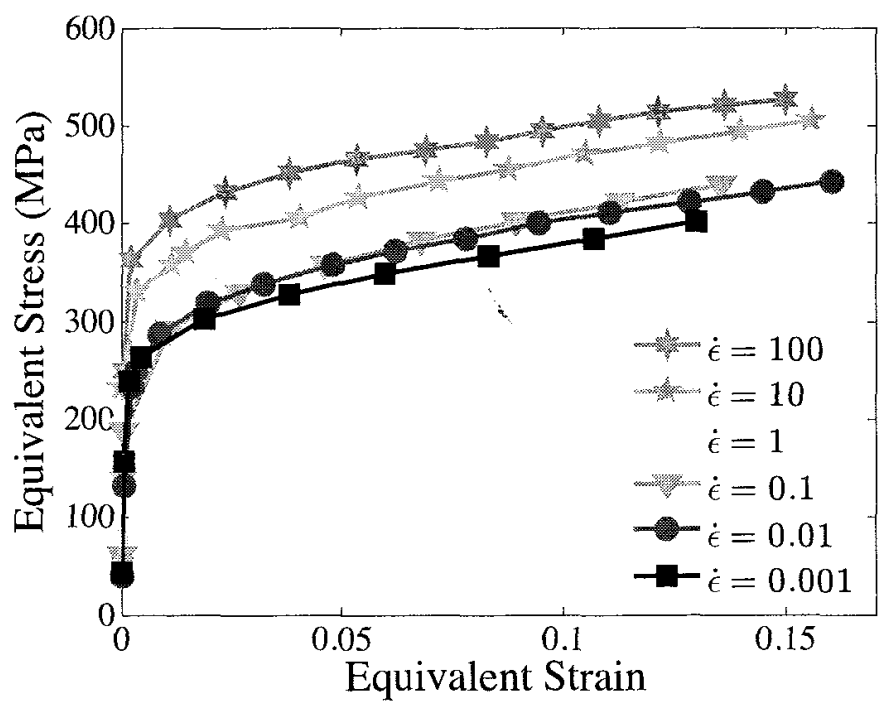

FIGURE 15. MEASURED FLOW STRESS-STRAIN RELATION FOR TUBE SPECIMENS AT 6 STRAIN RATES [17]

large deformation for the sheet steel specimen cut from the tube. As we are considering isotropic behavior, the shear test results were interpreted in terms of the equivalent von-Mises quantities. As observed in Fig. 15, the material behavior depends on the strain rate applied. Thus it is necessary to define the material behavior using a thermoviscoplastic constituve relation taking into account strain rate sensitivity. In our case and as a first approach, we employ the artificial method of introducing strain rate sensitivity by adjusting the yield stress based on the strain rate. The maximum strain rate observed for a pressure of 3 bar was approximately $500 \mathrm{~s}^{-1}$. This first approach may be used since we observed for our material an additive behavior inducing the same hardening for each strain rate, only the yield stress value is shifted.

\section{SINGLE DEGREE OF FREEDOM COMPUTATIONS}

The simplest theoretical model of the dynamics of a tube wall considers a section of the tube subjected to uniform timedependent loading with purely radial motion. If the stresses in the tube wall are assumed to be constant, and displacements are small compared to the tube radius $R$, then the equation of motion for such a system is

$$
\rho h \frac{d^{2} x}{d t^{2}}+\frac{h}{R} \sigma=\Delta P(t)
$$

For purely elastic motions, the membrane stress in the tube wall is related to the strain by

$$
\sigma=\frac{E}{1-v^{2}} \varepsilon_{\theta}
$$

and the hoop strain $\varepsilon_{\theta}$ is

$$
\varepsilon_{\theta}=\ln \left(\frac{R+x}{R}\right) \approx \frac{x}{R} \text { for }|x| \ll R
$$

Thus the equation of motion becomes

$$
\rho h \frac{d^{2} x}{d t^{2}}+\frac{E h}{R^{2}\left(1-v^{2}\right)} x=\Delta P(t)
$$

This is the equation for a forced harmonic oscillator with natural frequency

$$
\omega=\frac{1}{R} \sqrt{\frac{E}{\rho\left(1-v^{2}\right)}}
$$

So the period of the hoop oscillation of the cross section is $T=2 \pi / \omega$, which for the tubes used in the present study comes out to $73 \mu \mathrm{s}$. This is also four times the characteristic response time for the cross section to a differential pressure loading.

The single degree of freedom model may also be extended to the plastic regime by returning to Eq. 6 and introducing an inelastic stress-strain relationship. For our purposes, an elastoplastic model with linear strain hardening was chosen. In such a system,

$$
\begin{aligned}
& \sigma=E_{1} \varepsilon \text { for } \sigma<\sigma_{y} \\
& \sigma=\sigma_{y}+E_{2}\left(\varepsilon-\varepsilon_{y}\right) \text { for } \sigma>\sigma_{y} .
\end{aligned}
$$


In order to apply this material model with hardening, we must keep track of the yield strain as it increases in the plastic regime. This is done by evolving the yield stress with time, which for the linear strain hardening model requires integrating the evolution equation

$$
\frac{d \sigma_{y}}{d t}=E_{2} \frac{d \sigma_{y}}{d \sigma} \frac{d \varepsilon}{d t}
$$

where hardening only takes place with positive strain rates in the present problem

$$
\frac{d \sigma_{y}}{d \sigma}=\left\{\begin{array}{l}
1 \sigma \geq \sigma_{y} \\
0 \sigma<\sigma_{y}
\end{array}\right.
$$

The values of $E_{1}, E_{2}$, and $\varepsilon_{y, 0}$, the strain at which yielding initially occurs, are given in Table 4 . These values are chosen by approximately fitting the material properties shown in Fig. 15 for an intermediate strain rate.

This model has been implemented in Matlab using the Runge-Kutta solver ode45. The most relevant results to the present study are obtained when run in a loop over spatial locations in the tube, using $P(x, t)$ from the pressure model described in the previous section. The results corresponding to the five subsequent 2 bar initial pressure detonation loadings are shown in Fig. 16.

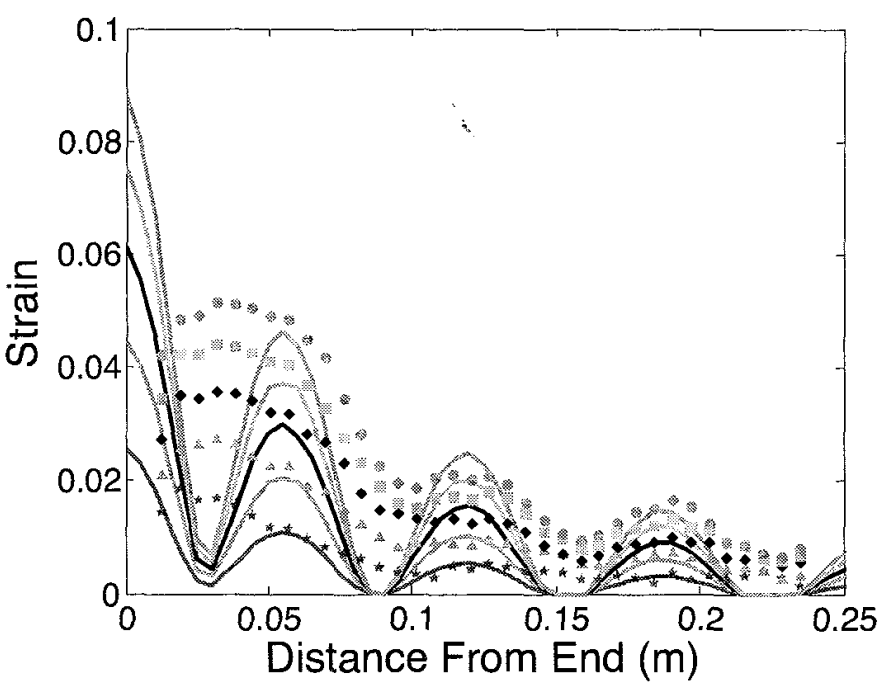

FIGURE 16. SINGLE DEGREE OF FREEDOM MODEL RESULTS FOR RESIDUAL PLASTIC STRAIN FOR 5 SUBSEQUENT 2 bar INITIAL PRESSURE DETONATION LOADINGS

The most striking thing about these results is the presence of the ripples that were noted in the experiment. The rippling is present in one-dimensional single degree of freedom calculations, which are free of any effect of boundary conditions or bending stresses, demonstrating that the underlying cause of the phenomenon is the loading history. The incident detonation sets the wall of the tube in elastic vibration at the natural frequency of the cross-section. The subsequent arrival of the reflected shock then imposes a second impulsive pressure loading on the already vibrating wall. Depending on the phase of the oscillation at the time when the shock wave arrives, the reflected shock loading may either augment or diminish the tube deformation. In the range of deformation produced by the tests at 2 bar initial pressure, the plastic deformation is of just the right magnitude so that the elastic oscillations and plastic deformation combine to yield periodic ripples. This is illustrated in Fig. 17, which shows the local strain traces for both a local minimum and a local maximum in the ripple pattern.

Knowing the mechanism behind the formation of the rippled pattern allows the calculation of the ripple wavelength. This is dependent on the reflected shock velocity, which increases in the expansion wave and decreases beyond the expansion tail, so it is presented in terms of the average shock velocity $\bar{U}_{R}$. The total time between the arrival of the detonation wave and the reflected shock at a given location $x_{0}$ is

$$
\begin{aligned}
\Delta t & =\frac{x_{0}}{U_{C I}}+\frac{x_{0}}{\bar{U}_{s}} \\
& =\frac{\bar{U}_{R}+U_{C J}}{\bar{U}_{R} U_{C J}} \cdot x_{0}
\end{aligned}
$$

and the total time difference required for the reflected wave to arrive at locations $360^{\circ}$ out of phase of the elastic oscillations of a given point is

$$
\Delta t_{2}-\Delta t_{1}=\frac{1}{f_{x s}}
$$

where $f_{x s}$ is the natural frequency of the cross section. Thus the wavelength of the ripples, $\lambda_{r}$ is found as

$$
\lambda_{r}=x_{2}-x_{1}=\frac{1}{f_{x s}}\left(\frac{\bar{U}_{R} U_{C I}}{\bar{U}_{R}+U_{C I}}\right)
$$

Testing this expression with the numbers for the 2 bar condition used in the experiment, $U_{C J}=2400 \mathrm{~m} / \mathrm{s}, f_{X s}=11 \mathrm{kHz}$, and the average velocity of the reflected shock computed from its arrival time at the last strain gauge, $\bar{U}_{R}=1250 \mathrm{~m} / \mathrm{s}$, the resulting wavelength is $75 \mathrm{~mm}$. The first two experimentally measured peaks are $80 \mathrm{~mm}$ apart from one another and the second and third are separated by $70 \mathrm{~mm}$.

Figure 16 illustrates the most obvious failing of the model. In a one-dimensional simulation, there is no modeling of the boundary condition. Thus the single degree of freedom model computes high strains at the reflecting end when, per the boundary conditions, none are allowed. The characteristic bending 
TABLE 4. MATERIAL PROPERTIES USED IN SINGLE DEGREE OF FREEDOM CALCULATIONS

\begin{tabular}{|c|c|c|c|c|c|c|}
\hline$E_{1}(\mathbf{G P a})$ & $E_{2}(\mathbf{G P a})$ & $\varepsilon_{y}$ & $R(\mathrm{~mm})$ & $h(\mathrm{~mm})$ & $\rho\left(\mathrm{kg} / \mathrm{m}^{3}\right)$ & $v$ \\
\hline 210 & 1 & 0.003 & 63.5 & 1.5 & 7800 & 0.3 \\
\hline
\end{tabular}

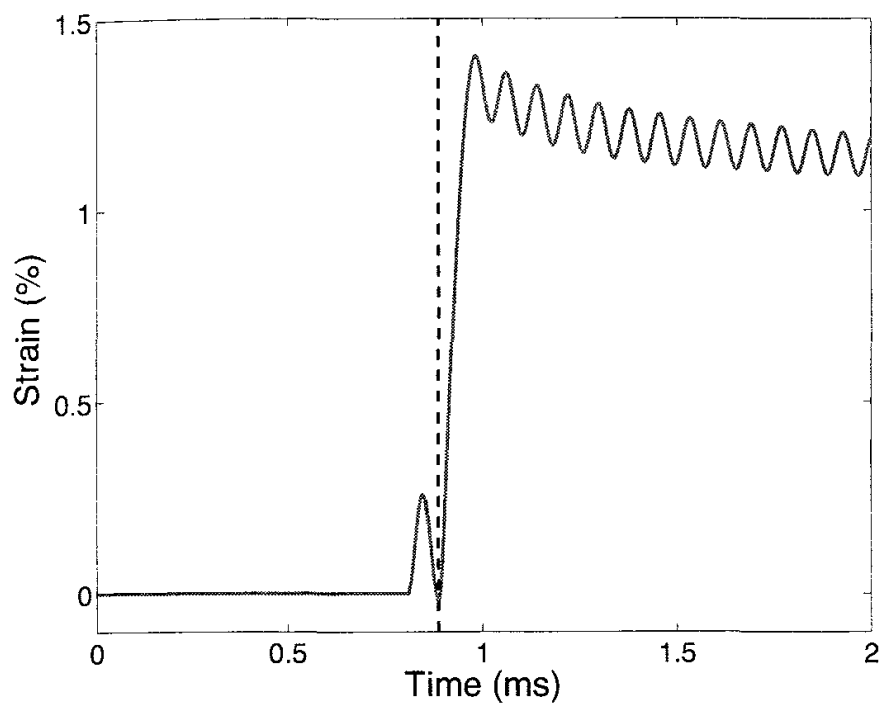

(A)

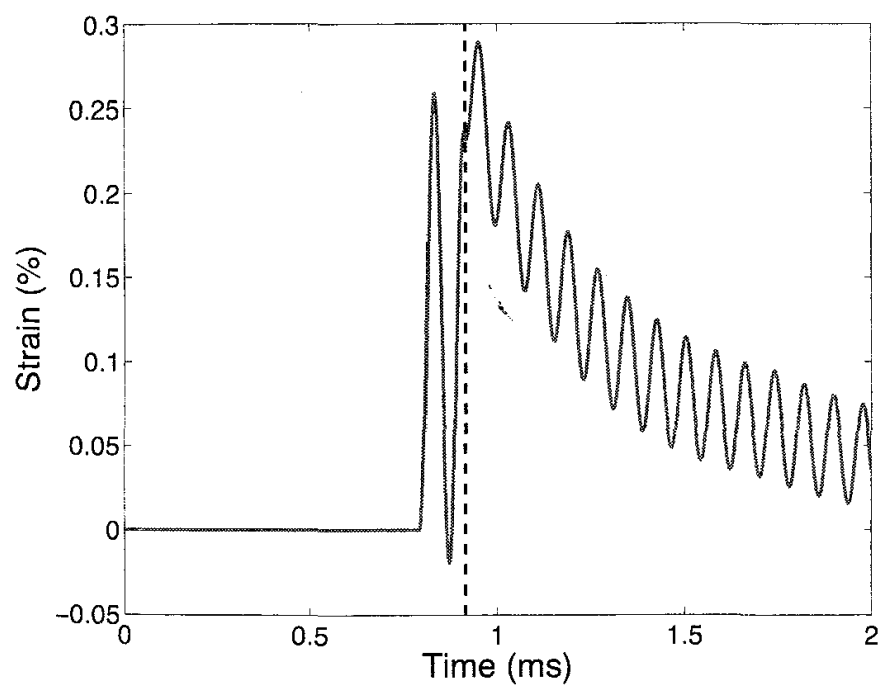

(B)

FIGURE 17. POINTWISE STRAIN TRACES COMPUTED FROM SDOF MODEL FOR (A) A PEAK AT $x=55 \mathrm{~mm}$ AND (B) A TROUGH AT $x=90 \mathrm{~mm}$ IN THE RIPPLE PATTERN IN FIG. 16. DASHED LINE INDICATES THE ARRIVAL TIME OF THE REFLECTED SHOCK.

length in the axial direction for a cylindrical shell is [18]:

$$
\lambda_{b}=\left[\frac{R^{2} h^{2}}{3\left(1-v^{2}\right)}\right]^{1 / 4}
$$

For the tubes used in this study, $\lambda_{b}=7.6 \mathrm{~mm}$. Thus from Fig. 16, the single degree of freedom model would appear to be reasonable for use with locations greater than about 3 to 6 bending lengths or 0.02 to $0.04 \mathrm{~m}$ away from the wall. Once beyond this bending length limit, the single degree of freedom model with the simple elastic-linear hardening constitutive relation does a remarkably good job of capturing both the locations and magnitudes of the local maxima for the series of tests at 2 bar initial pressure. The errors in the axial locations of the peaks is always within $10 \%$ of the wavelength, and the errors in residual plastic strains are within $30 \%$. The troughs of the ripple pattern are consistently underestimated by the single degree of freedom model, to the extent that residual plastic strain goes to zero for most of them. This is due to the single degree of freedom model neglecting bending and the production of flexural waves which couple the radial deformation of adjacent axial sections of the tube.

The overall usefulness of the single degree of freedom model lies in its simplicity. For small computational expense, it produced reasonably accurate computations of the residual plastic strain resulting from a reflecting detonation for axial locations several bending lengths away from the reflecting boundary and allowed us to explain the phenomenon of rippling in the tube wall. For more accurate numerical computations, we turned to a finite element solution that took the boundary conditions and a more realistic material model into account.

\section{FINITE ELEMENT SIMULATIONS}

A more sophisticated computational investigation of the problem involves the use of the method of finite elements. For the results reported herein, the finite element solver LS-DYNA V970 was used [19]. The tube was modeled using axisymmetric shell elements. Typically 5 elements were used through the thickness and 4000 through the tube length, which was taken to be $2 \mathrm{~m}$. This was in an effort to mimic the overall length of the tube assembly used in the experiment. The driver tube was not modeled separately, as we are most concerned with the deflection in the vicinity of the reflecting end.

The simplest simulations performed with the finite element model did not include the effects of strain-rate hardening, rather an average value of the yield strain was chosen and considered constant. For both cases the tangent modulus was taken to be $1 \mathrm{GPa}$. The yield strain was iterated until reasonable agreement was found with the residual plastic strains from the computation and those from the diameter measurements taken after each experiment. In the end, a value of $0.125 \%$ was chosen as the yield strain for the 2 bar case, and a value of $0.28 \%$ for the 3 bar case. The difference in the yield strains which reproduce the measured results underscores the necessity to include rate-hardening as a 
TABLE 5. MATERIAL PROPERTIES USED IN THE FINITE ELEMENT SIMULATIONS

\begin{tabular}{|l|c|c|c|c|c|c|}
\hline Model & $\begin{array}{c}E_{1} \\
(\mathbf{G P a})\end{array}$ & $\begin{array}{c}E_{2}(\mathbf{G P a}) \\
\varepsilon_{y}<\varepsilon<0.025\end{array}$ & $\begin{array}{c}E_{3}(\mathbf{G P a}) \\
\varepsilon>0.025\end{array}$ & $\varepsilon_{y 0}$ & $C$ & $P$ \\
\hline 2 bar bilinear & 210 & 1 & N/A & 0.00125 & N/A & N/A \\
\hline 3 bar bilinear & 210 & 1 & N/A & 0.0028 & N/A & N/A \\
\hline Cowper-Symonds & 210 & 3 & 1 & 0.0013 & 2000 & 6.6 \\
\hline
\end{tabular}

component of the material model.

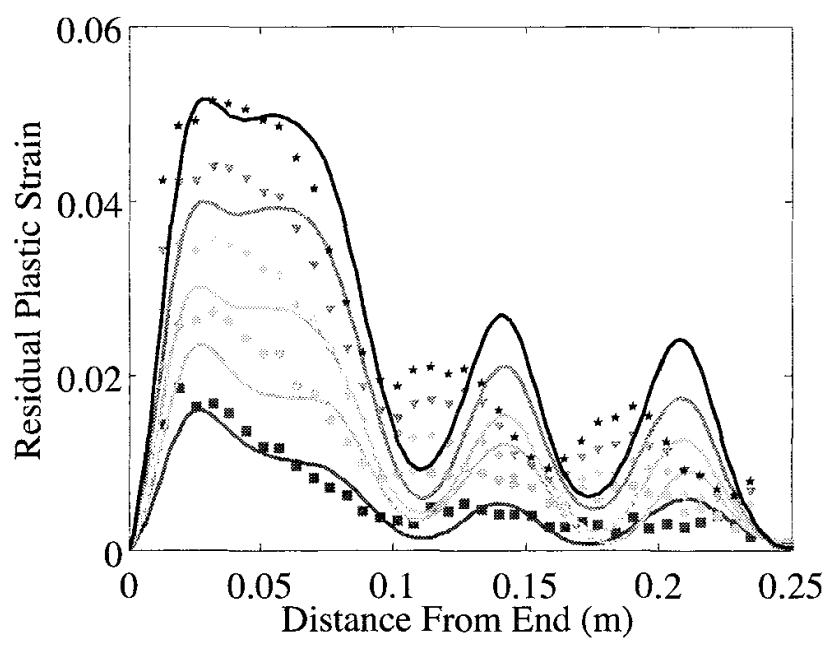

(A)

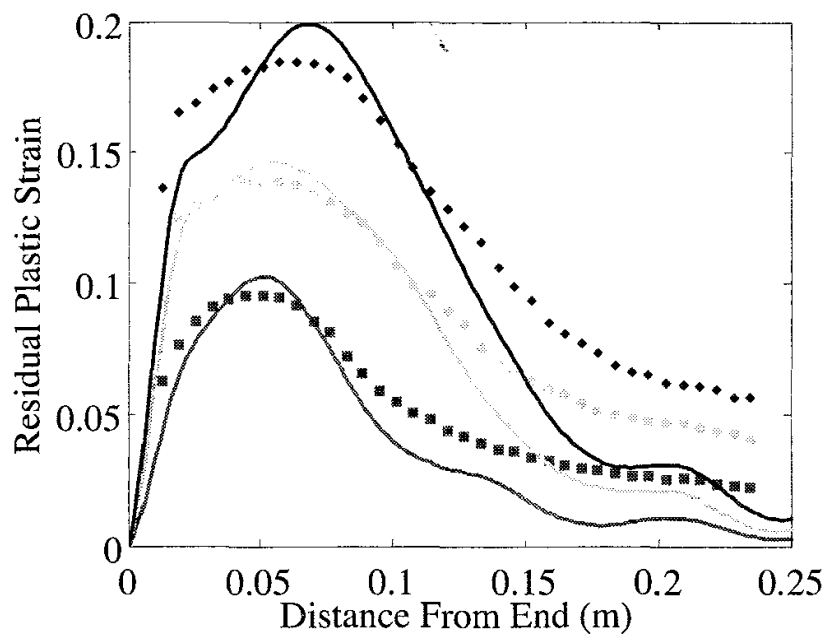

(B)

FIGURE 18. COMPARISONS OF MEASURED AND LS-DYNA COMPUTED RESIDUAL PLASTIC STRAINS FOR (A) 2 bar AND (B) 3 bar INITIAL PRESSURE USING THE ELASTIC-LINEAR HARDENING MODEL WITH NO RATE-HARDENING

Figure 18 contains plots showing the residual plastic strain calculated from these models in LS-DYNA and the corresponding experimental measurements. With the proper choice of yield strain, the bilinear model gives reasonable agreement with the experimental data. Note that the local maxima in the rippled pattern are consistently too high in the 2 bar case. This is most likely due to the simplifications involved in choosing a linear strainhardening curve, as the real material is stiffer at low strains than it is at high strains. Also note that the strains in the 3 bar case are low by a factor of 2 or more upstream of the primary bulge. This indicates that rate-hardening plays an important role in the 3 bar case even over the course of a single experiment, a fact which is further illustrated by the record of maximum strain-rate as calculated in LS-DYNA, shown in Fig. 19.

Figure 20 contains the residual plastic strains calculated using a model with a piecewise linear hardening curve and CowperSymonds rate-hardening. The model was designed with a bilinear strain-hardening curve with a tangent modulus of $3 \mathrm{GPa}$ between yield and $2.5 \%$ strain and $1 \mathrm{GPa}$ above that. The CowperSymonds parameters and the yield strain at zero strain-rate were fit to the data using least squares error minimization, and the values used in the final computations were $0.13 \%$ strain, $C=2000$, and $P=6.6$. The results of the fit are shown in Fig. 21 .

The key thing to note in the comparison shown in Fig. 20 is that the two computations were performed using the same material model. Only the loading conditions were changed. In comparing measured peak strains with computed quantities, the greatest deviation occurred in the 2 bar case, where it was $15 \%$. There was a narrow region between 0.02 and $0.05 \mathrm{~m}$ from the reflecting end in which the computed strain rose above the measured value. This indicates that the transition from $3 \mathrm{GPa}$ to $1 \mathrm{GPa}$ in the tangent modulus was either too sharp or occurred at too low a strain. The greatest error aside from the last three 2 bar tests occurred in the third 3 bar case, and was only $3 \%$. The error at this condition was substantially in excess of the first two loading cycles of either tube. We speculate that this was due to the fact that this strain level was beyond the conditions for which we have measured the material response.

The model appears to be too hard when we are away from the peak strain in the 3 bar case; this may be the result of too early or steep a transition in tangent modulus. Also, the computations performed with both material models exhibit large deviations from experiment in both the locations and amplitudes of the local maxima in the ripple patterns. The amplitudes are as much as $30 \%$ high, and the peaks are displaced by as much as 


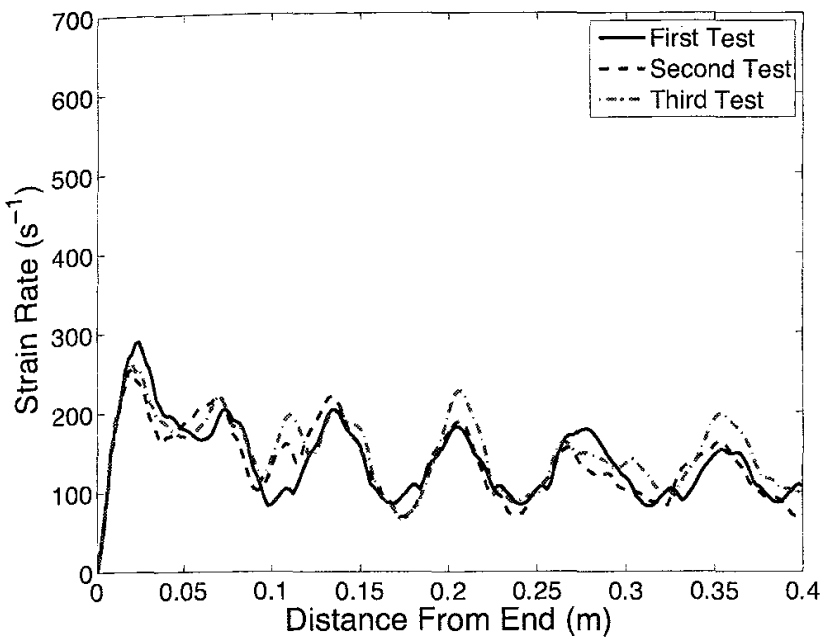

(A)

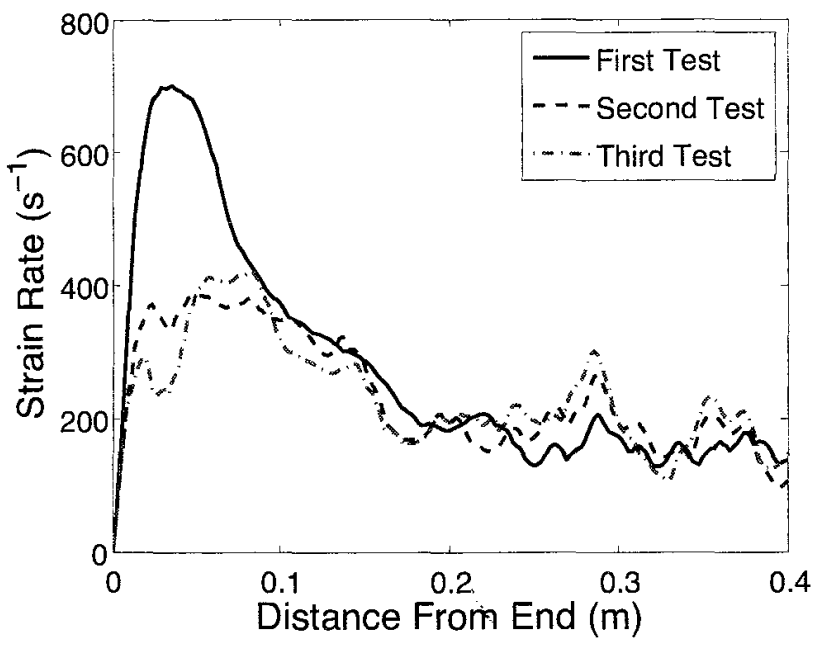

(B)

FIGURE 19. MAXIMUM STRAIN RATE CALCULATED FOR REPEATED (A) 2 bar AND (B) 3 bar EXPERIMENTS

$35 \%$ of a wavelength. This is because of the way in which the pressure loading was applied to the finite element model. The pressure loading is a boundary condition imposed on the wall, with a trajectory computed from the model for an undeformed wall. When the reflected shock wave causes radial deformations, the overall length of the tube shortens, causing the axial distance from elements to the end wall to decrease. The net effect is an apparent increase in reflected shock velocity.

Figure 22 contains comparisons of the measured and calculated strain traces for several locations along the tube. It is observed that the computational results exhibit a sharper rise in strain when the reflecting shock arrives. We hypothesize that this is due to the previously discussed over-idealization of the pressure model. All of the computational results assumed a sharp rise in pressure caused by the reflected shock, but in the experimental results a more gradual pressure rise is observed.

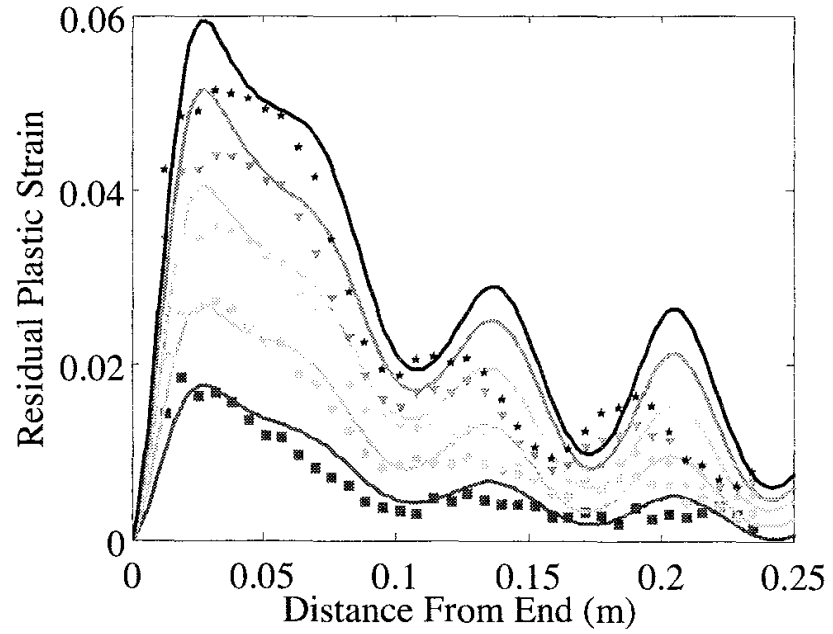

(A)

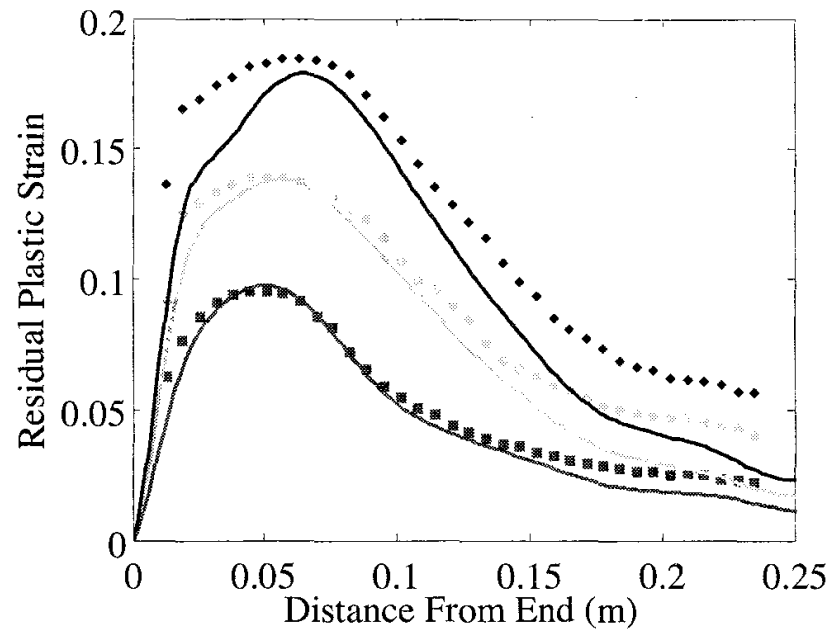

(B)

FIGURE 20. RESIDUAL PLASTIC STRAIN FOR (A) 2 bar AND (B) 3 bar WITH COWPER-SYMONDS RATE-HARDENING

A comparison of the time difference between the moment of reflection and the arrival times of the reflected waves reveals that on average the reflected wave in the model is travelling $3 \%$ faster than its laboratory counterpart. There are two factors which contribute to the velocity deficit: First, the idealized loading applied to the finite element mesh does not take into account the deformation of the tube. The boundary condition at the upstream end allows axial translation, which means that the tube shortens over the course of the calculation, just as it does in the experiment. This shifts the relative axial locations of the elements toward the reflecting end, while the reflected shock velocity was calculated as if no such displacement occured. The net effect is to increase the apparent shock velocity. Second, the shock pressure is decoupled from the material deformation. This would seem to be less important than the first effect, since this would also be a problem in the single degree of freedom case, which shows much greater fidelity in the peak locations. 


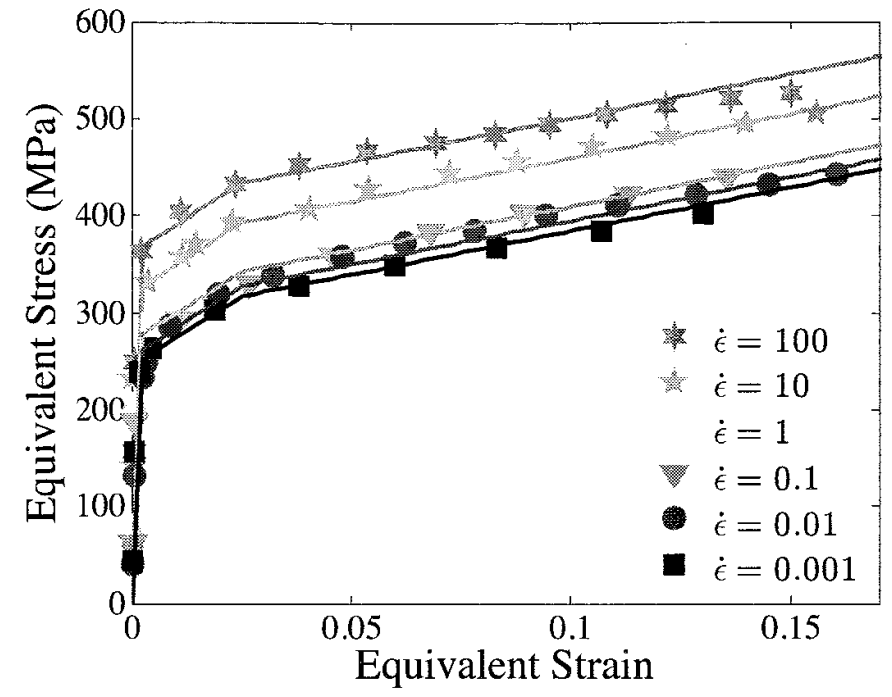

FIGURE 21. RATE-HARDENING MODEL USED IN COMPUTATIONS, COMPARED WITH MEASURED DATA FOR C1010 MILD STEEL [17]

\section{CONCLUSION}

Gaseous detonations create pressure rises that can cause plastic deformation of pipes and tubes. We constructed a detonation tube outfitted with strain and pressure gauges so that the deformation from these detonations and associated reflected shock waves may be studied. In so doing, we discovered an unusual rippling pattern in detonations of modest ( 2 bar) initial pressure and a long-time $(\sim 1 \mathrm{~ms})$ deformation for tubes of larger initial pressure ( 3 bar) subject to repeated loading.

The next step in this problem was to develop a computational model of the experimental results. To do so, a model of the pressure loading and a realistic material model that accounted for strain rate hardening were needed. A semi-empirical pressure model was developed that used theoretical reflected CJ values alongside the pressure trace in the tube's reflecting end, which was present for all experiments, and assumed there was no spatial gradient in pressure between the reflecting end and the shock wave. This model was found to accurately predict the shock strength and location. Dynamic strain data produced with a double shear test was used to account for strain-rate hardening which was found to have a substantial effect for strain rates present in detonation loadings.

Using a bilinear fit to the material data, a single degree of freedom model was employed. This model explained the rippling pattern observed in the 2 bar shots as due to the interference of the reflected shock wave loading with the oscillation set up by the initial detonation. Several material models were attempted for use in finite element computations before we settled on using a Cowper-Symonds model to account for the strain-rate hardening. With this material model, reasonable agreement was obtained between the experimental results and numerical computations.

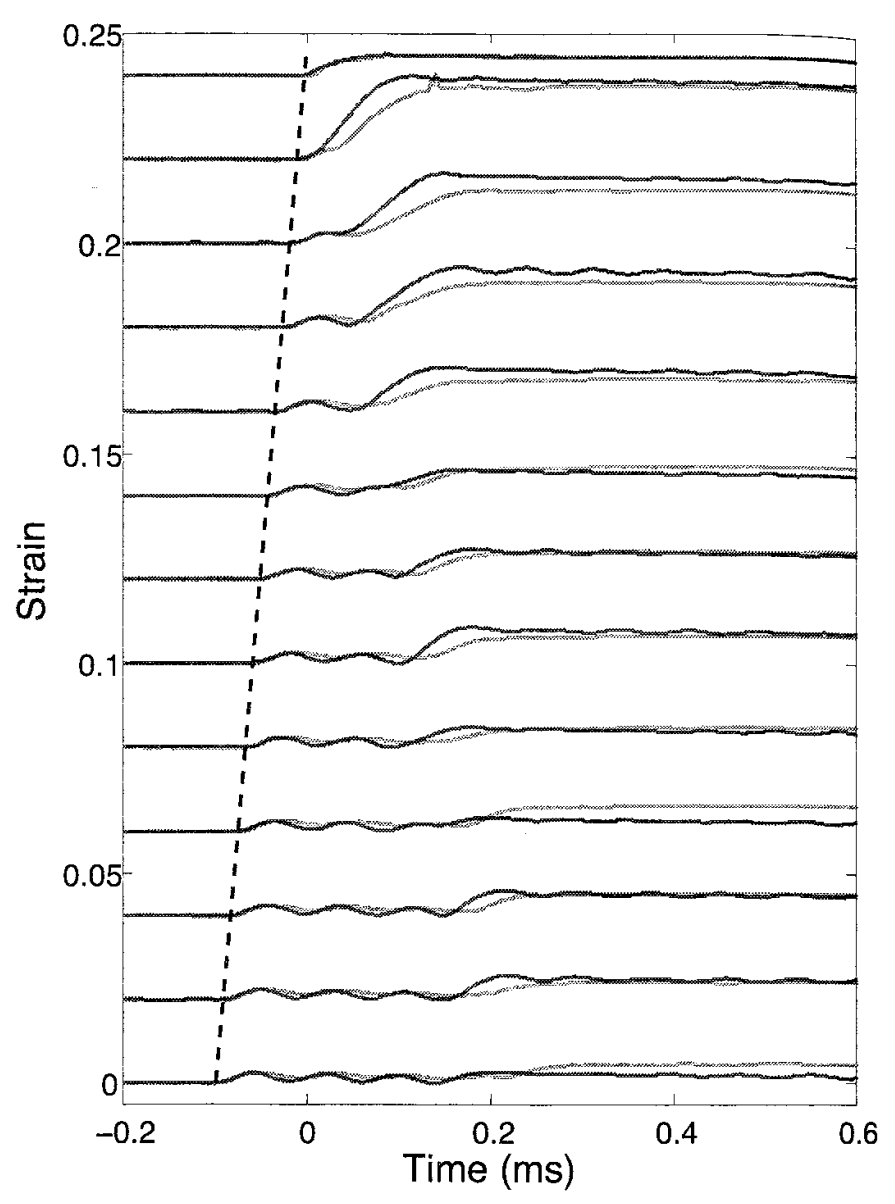

FIGURE 22. COMPARISONS OF STRAIN-TIME TRACES FOR THE 13 HOOP GAUGES CLOSEST TO THE REFLECTING END IN THE FIRST 2 bar TEST. EXPERIMENTAL TRACES IN RED, DYNA RATE-HARDENING MODEL IN BLUE. DASHED LINE INDICATES DETONATION ARRIVAL.

\section{ACKNOWLEDGEMENTS}

This research was sponsored by the Department of Homeland Security through the University of Rhode Island. DHSURI Center of Excellence for Explosives Detection, Mitigation and Response, Structural Response to Internal Explosions (URI Grant No. 12208-0001865, DHS Grant No. 2008-ST-061ED0002), project officer Dr. Jimmie Oxley. Prof. Rusinek carried out the double shear testing of the tube material at the University Paul Verlaine of Metz.

\section{REFERENCES}

[1] Lee, J. H. S., 2008. The Detonation Phenomenon. Cambridge University Press.

[2] Fickett, W., and Davis, W. C., 1979. Detonation. University of California Press, Berkerely, CA.

[3] Shepherd, J. E., 2009. "Structural response of piping to internal gas detonation". Journal of Pressure Vessel Technology, 131(3), June, pp. 87-115. 
[4] Shepherd, J., Teodorcyzk, A., Knystautas, R., and Lee, J., 1991. "Shock waves produced by reflected detonations". Progress in Astronautics and Aeronautics, 134, pp. 244264.

[5] Beltman, W., and Shepherd, J., 2002. "Linear elastic response of tubes to internal detonation loading". Journal of Sound and Vibration, 252(4), pp. 617-655.

[6] Karnesky, J., 2010. "Detonation induced strain in tubes". PhD thesis, California Institute of Technology.

[7] DASSAult Systémes SOLidWORKS CORP., 2007. SolidWorks Education Edition version 2007SP3.1. Concord, MA.

[8] Taylor, G. I., 1950. "The dynamics of the combustion products behind plane and spherical detonation fronts in explosives". Proc. Roy. Soc., A200, pp. 235-247.

[9] Zel'dovich, Y. B., 1940. "On the theory of the propagation of detonations in gaseous systems". JETP, 10, pp. 542568. Available in translation as NACA TM 1261 (1950).

[10] Zel'dovich, Y. B., and Kompaneets, A. S., 1960. Theory of Detonation. Academic Press, NY. English translation of original Russian.

[11] Wintenberger, E, Austin, J. M., Cooper, M., Jackson, S., and Shepherd, J. E., 2004. "Reply to "comment on analytical model for the impulse of single-cycle pulse detonation tube"'. Journal of Propulsion and Power, 20(5), pp. 957959.

[12] Radulescu, M. I., and Hanson, R. K., 2005. "Effect of heat loss on pulse-detonation-engine flow fields and performance". Journal of Propulsion And Power, 21(2), MarApr, pp. 274-285.

[13] Ziegler, J., 2010. private communication.

[14] Deiterding, R., 2003. "Parallel adaptive simulation of multi-dimensional detonation "structures". $\mathrm{PhD}$ thesis, Brandenburgische Technische Universitat, Cottbus, Germany, September.

[15] Browne, S., Zeigler, J., and Shepherd, J., 2008. Numerical solution methods for shock and detonation jump conditions. Tech. Rep. FM2006-006, Graduate Aeronautical Laboratories California Institute of Technology, February.

[16] Rusinek, A., and Kepaczko, J., 2001. "Shear testing of a sheet steel at wide range of strain rates and a constitutive relation with strain-rate and temperature dependence of the flow stress". International Journal of Plasticity, 17, pp. 87115.

[17] Sauvelet, C., Rusinek, A., Shepherd, J. E., Liang, Z., and Karnesky, J., 2007. "Elastic and plastic deformation waves in tubes with internal gas explosion". In ASME Applied Mechanics and Materials Conference., ASME. MCMAT2007-30024, presented June 3-7 2007 University of Texas at Austin.

[18] Young, W., and Budynas, R., 2002. Roark's formulas for stress and strain. McGraw-Hill. Seventh Edition.

[19] Livermore SOFtware TeCHnOlOGy Corporation, 2005. LS-DYNA User's Manual, version 971. Livermore, CA. 